\title{
Effects of thinning and pruning on stem and crown characteristics of radiata pine (Pinus radiata D. Don)
}

\author{
M Paulina Fernández ${ }^{(1-2)}$, \\ José Basauri ${ }^{(3)}$, \\ Carolina Madariaga ${ }^{(3)}$, \\ María Menéndez-Miguélez ${ }^{(1)}$, \\ Ricardo Olea ${ }^{(4)}$, \\ Ane Zubizarreta-Gerendiain ${ }^{(5-6)}$
}

\begin{abstract}
Simultaneous applications of thinning and pruning are common silvicultural practices in radiata pine (Pinus radiata) forest plantations. Their separate effects on tree growth and wood quality have been well studied, but their combined effect is not clear yet. The aim of this study is to identify how thinning and pruning together affect the stem structure and properties of the pruned but also the unpruned section of the trees (the portions formed immediately after the application of these management efforts). The effects of pruning and thinning on the number of growth units per year, internode length, number of branches, and branch diameters was analyzed in managed and unmanaged stands of radiata pine grown in Chile. When used jointly, these practices generated larger individual tree volumes $(135 \%$ more) and clear wood in the pruned logs; however, they also reduced the sawn wood quality of the unpruned stem section for some years after the silvicultural interventions. The managed trees showed more growth units per annual shoot and shorter internodes, thus generating more knotty wood. Moreover, managed trees showed more taper. As trees of the managed stand restore the foliar biomass lost due to pruning, managed and unmanaged stands approach the same level of canopy closure, and differences minimize.
\end{abstract}

Keywords: Annual Shoot, Silviculture Management, Branching, Knots, Tree Volume, Taper, Wood Quality

space for the remaining trees and increasing light, temperature, and air currents inside the canopy (Peltola et al. 2007). As a general rule, the remaining trees grow more in diameter, developing larger crowns with bigger branches (Pape 1999, Gort et al. 2010), but the extent of this pattern depends on the growth potential and the thinning intensity (Meneses \& Velasco 1992). Pruning also has strong effects on tree structure, changing the photosynthetic capacity of the crown. In general, heavy pruning of green branches reduces
(1) Department of Ecosystems and Environment, Faculty de Agronomy and Forest Engineering, Pontificia Universidad Católica de Chile, Av. Vicuña Mackenna 4860, Macul, Santiago (Chile); (2) UC Timber Innovation Center, Pontificia Universidad Católica de Chile, Av. Vicuña Mackenna 4860, Macul, Santiago (Chile); (3) Undergraduate School of Forest Engineering, Faculty de Agronomy and Forest Engineering, Pontificia Universidad Católica de Chile, Av. Vicuña Mackenna 4860, Macul, Santiago (Chile); (4) Department of Statistics, Faculty of Mathematics, Pontificia Universidad Católica de Chile, Av. Vicuña Mackenna 4860, Macul, Santiago (Chile); (5) University of Eastern Finland, School of Forest Sciences, Yliopistokatu 7, FI80101 Joensuu (Finland); (6) Basque Centre for Climate Change (BC3), 48008, Bilbao (Spain)

@ M Paulina Fernández (pfernan@uc.cl)

Received: Mar 02, 2016 - Accepted: Oct 20, 2016

Citation: Fernández MP, Basauri J, Madariaga C, Menéndez-Miguélez M, Olea R, ZubizarretaGerendiain A (2017). Effects of thinning and pruning on stem and crown characteristics of radiata pine (Pinus radiata D. Don). iForest 10: 383-390. - doi: 10.3832/ifor2037-009 [online 2017-03-16]

Communicated by: Giacomo Goli the photosynthetic capacity of trees, decreasing their growth (Neilsen \& Pinkard 2003) and producing more cylindrical trees (Zobel \& Van Buijtenen 1989). Some studies pointed out that the remaining branches grow bigger after pruning (Meneses \& Velasco 1992), but the pruned stem part shows different wood quality characteristics, with less knots and higher wood value for sawn timber (Mäkinen et al. 2014).

In radiata pine (Pinus radiata) grown in Chile, which nowadays is the most important tree species in the sawn lumber industry, actual wood production is currently showing the effects of the intensive silviculture practices applied in the last 30 years, with emphasis on a combination of thinning and pruning intended to increase clear wood production. In common silvicultural regimes in Chile, highly productive site conditions use an initial stocking of 1111 to 1250 trees ha', with four pruning events when dominant trees reach a height of 7.6, 10,13 and $17 \mathrm{~m}$, with pruning height at 2,3 , 5.3 and $5.5 \mathrm{~m}$, respectively. Typically, there are around 550 to 650 pruned trees per hectare during the two first prunings and 200 to 350 trees in the remaining two. At the time of the first pruning, a first thinning of the non-pruned trees is completed, leaving 550 to 650 trees per hectare. Later on, when trees reach a dominant height of 13 $\mathrm{m}$, the second thinning is applied. Variations of this silvicultural regime are done depending on site conditions. In low pro- 
ductive sites neither pruning nor thinning is applied if final production is focused on pulp production, or two thinnings with no pruning if sawn timber is intended (Cabello 2005).

Crown development of many conifers, including radiata pine, follows a rhythmic growth (Hallé et al. 1978). The shoot portion formed during one elongation phase without interruption is termed "a growth unit” (Caraglio \& Barthélémy 1997); within an annual growing season a tree produces a shoot that may be composed of one or more growth units, referred to as a monocyclic or polycyclic annual shoot, respectively (Fig. 1). Radiata pine shows a rhythmic growth (Pawsey 1964) and produces one or more growth units per annual shoot on the main stem. Therefore, it is considered a polycyclic species, even though in some years and/or climatic conditions some trees produce just one growth unit (Bannister 1962, Fernández et al. 2007).

The growth trend during the lifespan of radiata pine has been well described by Fernández et al. (2007). It shows an increasing number of growth units per annual shoot during the juvenile phase, but this number stabilizes as the tree reaches a sexually mature stage. Although the crown form and annual shoot pattern in an individual tree are partly determined by its genotype, a different phenotypical expression could be found every year (Bannister 1962, Fernández et al. 2007). The number of annual growth units is not genetically fixed a priori; it depends on the environment, as Burdon (1971) demonstrated by comparing the same radiata pine clonal material in different site conditions.
The study of the tree crown is very important in terms of some wood properties. Branches determine the frequency and size of knots that will be present in the final processed wood, influencing the quality and price of sawn timber. Size and frequency of knots are the most important determinants of wood quality for sawn timber production (Haygreen \& Bowyer 1996) and it is dependent of forest management and competition by the neighboring trees (Zubizarreta-Gerendiain et al. 2009). Tree taper is another important quality parameter from the industrial perspective, as it is related to the efficiency of timber production (Haygreen \& Bowyer 1996). The term "tree taper" refers to the diameter difference along the tree stem. When this difference in a stem is large, there is an important decrease in efficiency and profitability.

In Chile, size and distribution of knots are considered when classifying sawn timber for both visual and mechanical qualities in radiata pine (Mezzano 1998). In New Zealand, Todoroki et al. (2001) performed a sensibility analysis of the relationship between log and branch characteristics and the yield of sawn timber of different quality grades on radiata pine. They determined that the smallest diameter in the log (related to the taper) and the length of internode (defined as the vertical distance in the stem between the upper part of a cluster of branches and the lower part of the following one - Fig. 1) were the variables that best correlated with sawn wood quality. The length of the internode is one of the most important factors for classifying the visual quality of sawn timber;

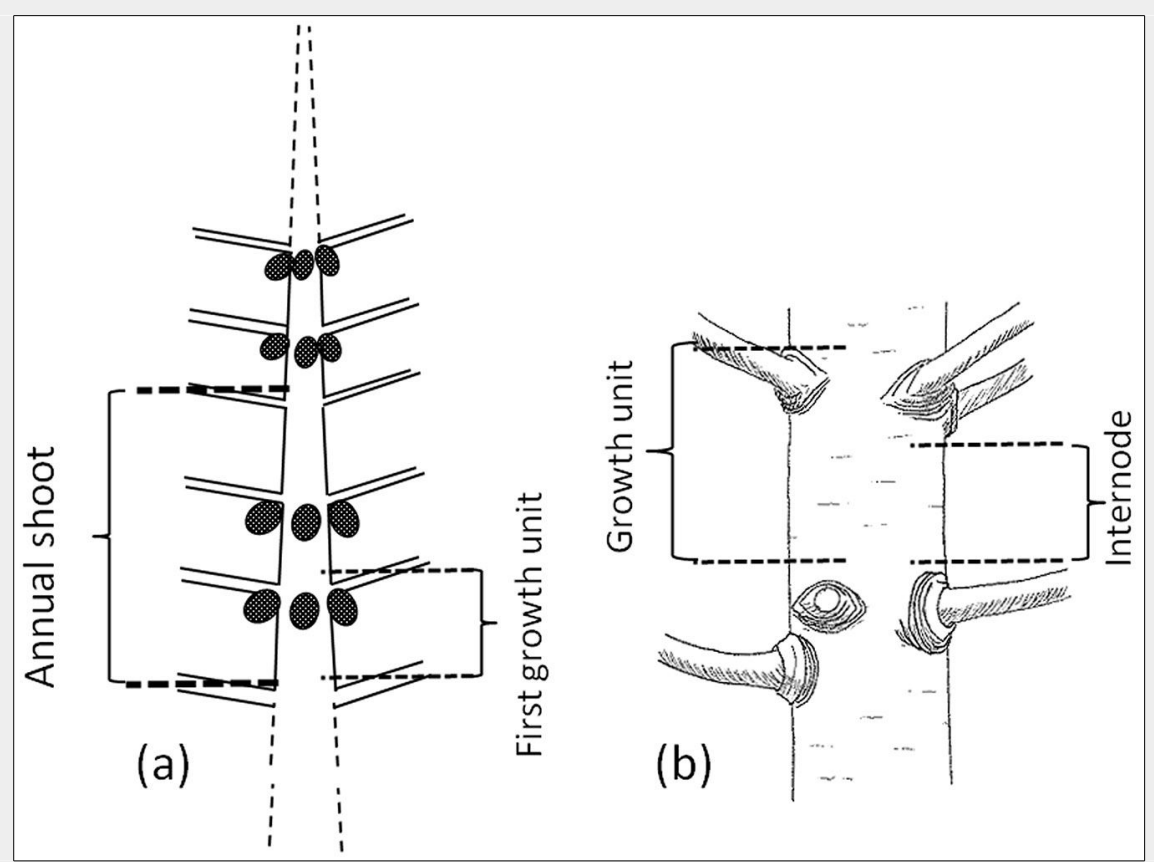

Fig. 1 - (a) Stem portion showing an annual shoot with three growth units. (b) Detail of growth unit limits from the upper part of the previous branch cluster to the upper part of the current cluster, the internode corresponds to the portion inside a growth unit that is free of branches (free of knots). longer internodes make it possible to produce more clear timber more efficiently.

In productive tree plantations in Chile, as well as in many other countries, it is common to manage stands simultaneously with thinning and pruning. Although the effects of each of these practices have been separately studied (for example, see Beets \& Madgwick 1988 for thinning and Neilsen \& Pinkard 2003 for pruning), the final effects of the combination of both treatments on wood properties and timber production have not been clearly determined (Clark et al. 2004). The study of these management alternatives together is very important in Chile, where thinning and pruning have been systematically done for the past 30 years. In particular, the effect on the non-pruned portion of the stem developed at the apex under the new conditions of the tree/stand after the interventions has not yet been analyzed. Therefore, the aim of this study was to determine the combined effects of thinning and pruning on the annual shoot, and therefore the eventual wood quality of radiata pine on the lower pruned section of the stem, but also including the upper section of the stem formed under the effects of the management practices. The hypothesis of the study was that thinning and pruning affect the newly formed stem section, thus affecting the final commercial product. To assess the effects, we studied: internode length; number of growth units per year (as well as length of growth units); and size, number, and frequency of branches in the newly formed stem section after the interventions, as in the rest of the stem. The final objective was to identify the real effect of the classical Chilean management practices on wood properties from the sawn industry point of view, analyzing not only the lower part of the stem, but also the upper part developed after the applied management practices in a medium productive site with non-bred genetic material.

\section{Material and methods}

\section{Material}

An 18-year-old radiata pine stand planted in 1982 was chosen for the study. The stand of 38 ha was divided in two plots later on, to carry out the study. The stand was located in Chile, in the "Comuna de Cobquecura" $\left(36^{\circ} 10^{\prime} \mathrm{S}, 73^{\circ} 70^{\prime} \mathrm{W}\right)$, Nuble province, VIII Region "Del Bío-Bío," in a temperate Mediterranean sub humid climate. At the beginning both plots were a single stand, growing under the same edafoclimatic conditions, coming from the same lot of seeds, without genetic breeding. The site has a site index of 26 (height attained at an age of 20 years) corresponding to a site of medium productivity. Annual mean precipitation in the location is $1134 \mathrm{~mm}$, with five months of drought; mean annual temperature is $13.8^{\circ} \mathrm{C}$, mean maximum temperature in summer is 23.9 
${ }^{\circ} \mathrm{C}$, and mean minimum temperature in winter is $5.9^{\circ} \mathrm{C}$ (Santibáñez \& Uribe 1993). The soil corresponds to the Cauquenes Series of medium fertile, well-drained slightly eroded soils of medium texture derived from granitic material (CIREN 1999) located in a terrain without slope.

The stand had an initial density of 2500 trees ha $^{-1}$ and after several years the original stand was split into two smaller plots. One of the plots was left unmanaged (the Unmanaged Stand, UMS - 26 ha), while the other plot was subject to several management treatments (Managed Stand, MS -12 ha). At year 6, a thinning leaving 1300 trees $\mathrm{ha}^{-1}$ and a light pruning up to 1.5 meters high were performed to all the trees in the MS plot; at year 11 another thinning leaving 600 trees $\mathrm{ha}^{-1}$ and pruning up to 6 meters high were carried out. There were no unpruned trees left in the pruned stand. At year 17, just one year before the harvesting and measurement of the trees, the last thinning without pruning was done in the managed stand. At the moment of felling and measuring the trees, the MS had a remaining stand density of 450 trees $h^{-1}$, all of them pruned up to 6 meters high while the UMS had a stand density of 2250 trees ha ${ }^{-1}$ because of natural mortality. After the measurement of the diameter and height of all trees of the plots, 30 trees from each plot were felled following their diameter distributions. Height and stem diameter at breast height (1.3 meters) of the sample trees were measured.

As radiata pine is a polycyclic species, more than one growth unit can be produced in one year. The whole growth of a circadian year is called an "annual shoot". The demarcations between growth units and annual shoots in the main stem were identified. The length of every growth unit was recorded from the insertion point of the upper structure (branch or cone) in the previous growth unit to the insertion point of the upper structure in the actually measured growth unit. The base diameter of every growth unit was also recorded $10 \mathrm{~cm}$ above the base limit of the growth unit to avoid the stem deformation produced by the presence of branches (Fig. 1). The variable internode was considered as proposed by Grace \& Carson (1993), which is the distance free of branches between two consecutive clusters of branches.

The data analysis consisted in (a) a morphological analyses of the 30 trees from each plot, and (b) a characterization of the logs.

\section{Morphological analysis}

The crown morphological analysis was done for the annual shoots from years 11 through 17, corresponding to the annual shoots formed after the second silvicultural intervention and located in the upper part of the crown. Year 11 was the first one analyzed since it was the first year where annual shoots could be clearly identified because of the branches (last pruning was done at year 11). The current annual shoot developing at the time of measurement (annual shoot from year 18) was not considered because it was not completed at the time of harvesting. The two plots were compared for the following variables: total length of the annual shoot, length and number of growth units per annual shoot, number of branches and cones per growth unit, average diameter of branches in the last growth unit of each annual shoot, and stem taper index per year, calculated as the difference in centimeters between the thickest and the thinnest part of an annual shoot, divided by the length in meters.

An initial classification or regression tree using Tree package of R (Ripley 2016) was carried out to observe the behavior of the different variables. A Repeated Measures ANCOVA with the time as the covariate was applied (Faraway 2016) using R statistical package (R Core Team 2016), to the variables annual shoot length, mean growth unit length per annual shoot, mean branch diameter in the last growth unit and stem taper index per year. For the variables number of growth units per annual shoot and number of branches and cones per growth unit, a robust ANCOVA (non-parametric) was carried out (Wilcox 2012) using the WRS2 package of R (Mair et al. 2016). The smoothed lines were obtained using the LSTS package of R (Olea et al. 2015).

To express the potential yield of wood pieces free of knots along the stem, an assessment proposed by Kininmonth \& Whiteside (1991) was used, counting the number of growth units longer than or equal to $75 \mathrm{~cm}$ per year. The critical value of $75 \mathrm{~cm}$ was used, build by at least $60 \mathrm{~cm}$ or more of clear internode wood $(60 \mathrm{~cm}$ is the critical value for short clear wood products in the local industry, particularly for the finger-joint processing) plus an estimated value of $15 \mathrm{~cm}$ equivalent to the branch cluster zone. Data was presented as frequency of growth units of different lengths under the two different conditions.

\section{Logs characterization}

For the characterization of the logs, we derived five virtual or composite logs of 4 meters each from the average values of each plot. Thereafter, and based on different wood property parameters, logs with average characteristics from the MS and UMS were statistically compared (F-test and t-test). This analysis included the lower stem part of the tree (growth prior to $11^{\text {th }}$ annual shoot), which was not considered in the morphological study. We compared the composite logs for, taper index $(T I)$ of the logs (eqn. 1), minimum diameter of the logs, and the logs' volume (eqn. 2) according to the Smalian formulae (Prodan et al. 1997). The taper index was calculated as follows (eqn. 1):

$$
T I=\frac{(\text { Dmax }- \text { Dmin })}{L}
$$

where Dmax is the maximum diameter of the log in $\mathrm{cm}, D \min$ is the minimum diameter of the $\log$ in $\mathrm{cm}$, and $L$ is the length of the log in $\mathrm{cm}$. All the logs were of $400 \mathrm{~cm}$ (4 $\mathrm{m}$ length). Log volume was estimated as (eqn. 2):

$$
V=\frac{\pi\left(\frac{D \max }{200}\right)^{2}+\pi\left(\frac{D \min }{200}\right)^{2}}{2} L
$$

where $V$ is the volume in $\mathrm{m}^{3}, D \max$ and Dmin are the diameters of the $\log$ in $\mathrm{cm}$, and $L$ is the length of the log in meters.

We also compared the logs' internode index (eqn. 3). The Internode Index (II) expresses the potential of the log for short clear pieces of wood (critical value of 60 $\mathrm{cm}$, corresponding to short clear wood), particularly useful in industrial processes as finger-joint production (Kininmonth \& Whiteside 1991). For calculation purposes, and having in the data the growth unit lengths instead of internode lengths, we assumed an average length of $15 \mathrm{~cm}$ per growth unit occupied by the branch cluster. Then the internode index was built by adding the length of growth units larger or equal to 75 $\mathrm{cm}$ length $(60 \mathrm{~cm}$ clear wood plus $15 \mathrm{~cm}$ branch cluster - eqn. 3):

$$
I I=\frac{\sum G U L \geq 75 \mathrm{~cm}}{L}
$$

where $G U L$ is the growth unit length $(\mathrm{cm})$ and $L$ is the length of the $\log (\mathrm{cm})$.

For the characterization of the whole stem, the average characteristics of the stems were calculated. The limits for the annual growth were not identified, but the branches/knots of the growth units were clear and easy to measure. Therefore, it was possible to calculate the average branch number in each log.

\section{Results}

At the beginning of year 11 (before the second management actions), the average height of the UMS trees was slightly smaller than the height of the MS trees (Tab. 1), with also slightly less growth units per annual shoot. These differences were most likely produced by the previous management actions at year 6 . At the time of harvesting (years 18), the average height for the sample trees was $24.75 \pm 3.37 \mathrm{~m}$ (mean \pm standard deviation) in UMS and $25.0 \pm 2.6 \mathrm{~m}$ in the MS stand. The diameter at breast height (DBH at $1.3 \mathrm{~m}$ ) in the UMS was $24.8 \pm 6.5 \mathrm{~cm}$ and $28.7 \pm 5.4 \mathrm{~cm}$ in the MS trees and the mean individual merchantable tree volume (upper limit diameter of $10 \mathrm{~cm}$ ) was $0.53 \pm 0.35 \mathrm{~m}^{3}$ in the UMS and $0.73 \pm 0.30 \mathrm{~m}^{3}$ in the MS. Based on the branch diameter measurements and assuming the allometric relationship between branch diameter and branch length described by Fernández \& Norero (2006), we estimated that stand closure (i.e., canopy closure) occurred at year 5 in both stands (previous to the first managements in the managed stand), and after the thinning of year 11 in the MS the stand closure occurred again between years 13 and 14 . 
Tab. 1 - Mean tree characteristics (total tree height - Height, m; diameter at breast height - DBH, cm; individual tree volume, $\mathrm{m}^{3}$; number of growth units per annual shoot - Annual GU), number of branches per growth unit (Branches per GU), taper of the stem (Taper) and their standard deviation in unmanaged stands (UMS) and managed stands (MS) at year 11 (before the second manage ment) and year 18 (before harvesting). Note: merchantable volume was obtained using $10 \mathrm{~cm}$ as top diameter.

\begin{tabular}{clcccccc}
\hline Year & Treatment & $\begin{array}{c}\text { Height } \\
(\mathbf{m})\end{array}$ & $\begin{array}{c}\text { DBH } \\
(\mathbf{c m})\end{array}$ & $\begin{array}{c}\text { Volume } \\
\left(\mathbf{m}^{3}\right)\end{array}$ & $\begin{array}{c}\text { Annual } \\
\text { GU }\end{array}$ & $\begin{array}{c}\text { Branches } \\
\text { per GU }\end{array}$ & Taper \\
\hline 11 & UMS & $11.8 \pm 2.9$ & - & - & $3.10 \pm 1.15$ & $6.5 \pm 1.4$ & $0.79 \pm 0.42$ \\
& MS & $13.9 \pm 2.9$ & - & - & $3.77 \pm 0.97$ & $6.0 \pm 1.2$ & $1.06 \pm 0.34$ \\
18 & UMS & $24.7 \pm 3.4$ & $24.8 \pm 6.5$ & $0.53 \pm 0.35$ & $2.73 \pm 1.26$ & $5.2 \pm 1.8$ & $1.21 \pm 0.64$ \\
& MS & $25.0 \pm 2.6$ & $28.7 \pm 5.4$ & $0.73 \pm 0.30$ & $3.21 \pm 1.14$ & $4.5 \pm 1.7$ & $1.55 \pm 0.87$ \\
\hline
\end{tabular}
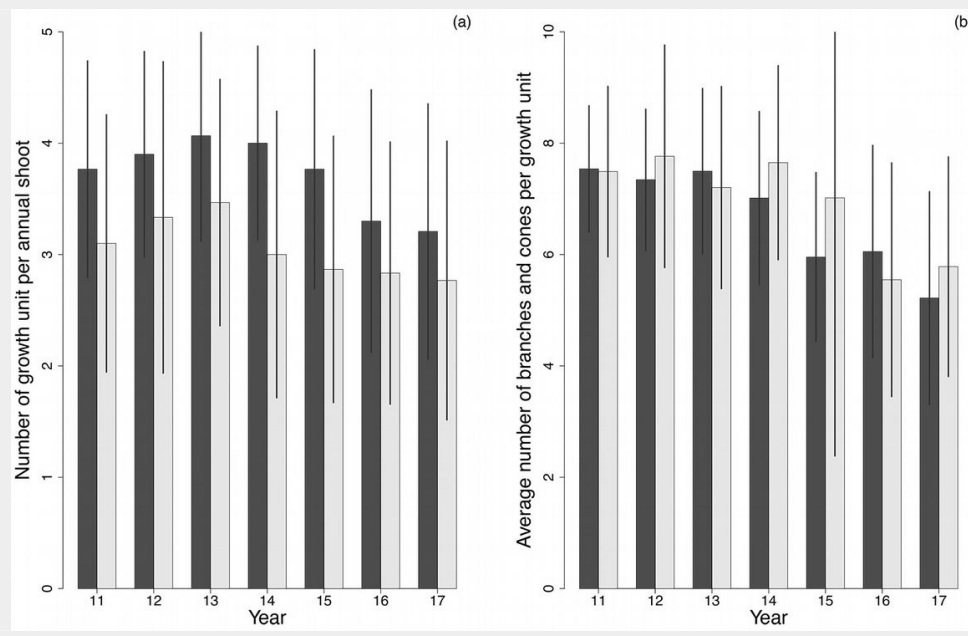

(b) Fig. 2 - (a) Number of growth units per annual shoot; (b) average number of branches and cones per growth unit. Error bars represent the standard deviation. MS corresponds to dark columns, UMS to light gray columns.
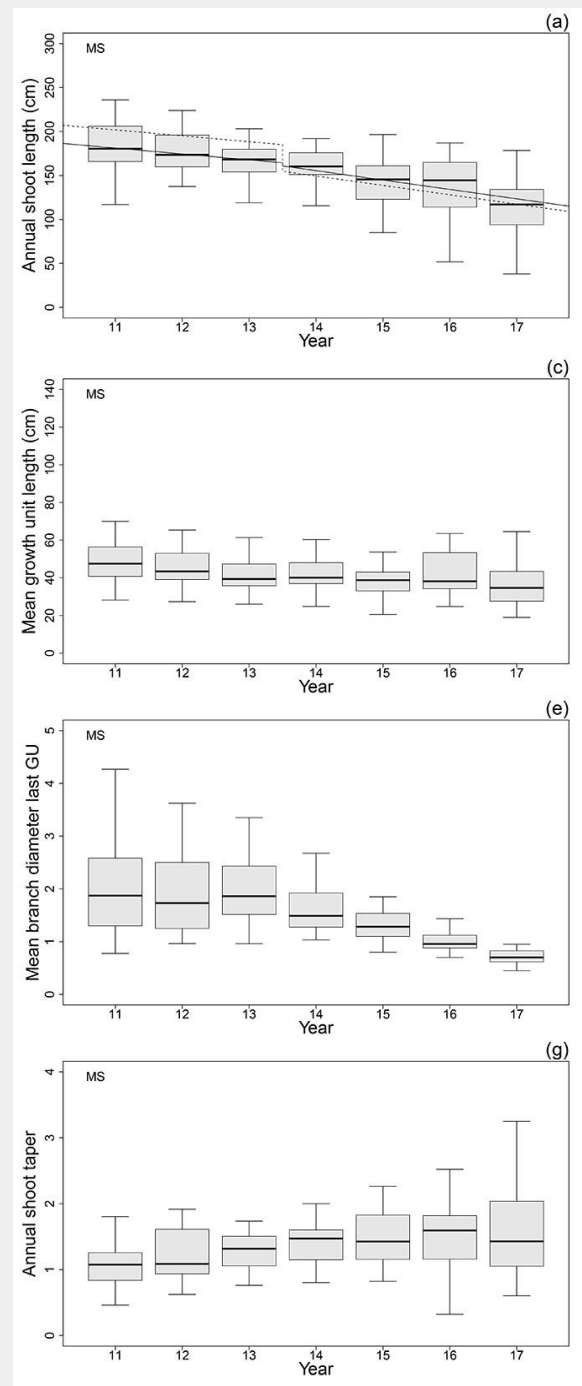
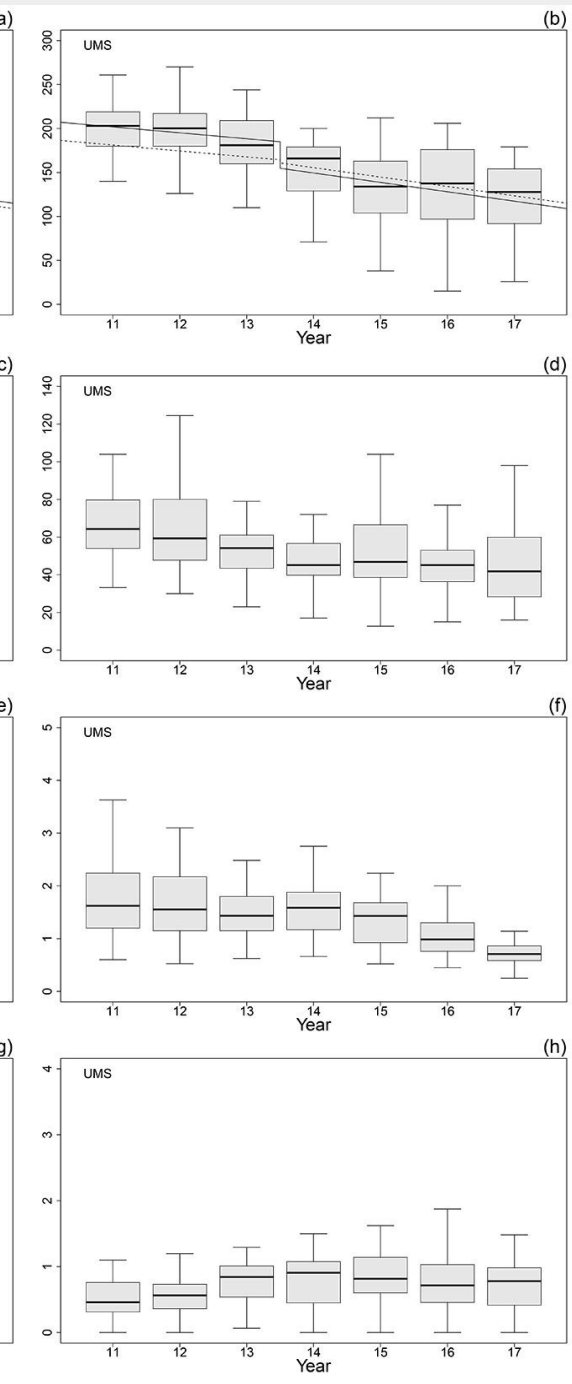

(b) and UMS (b) showing with continuous line the corresponding fitted model and with dashed line the model for the opposite treatment; mean growth unit length per annual shoot (cm) in MS (c) and UMS (d); mean branch diameter in the last growth unit per annual shoot in MS (e) and UMS (f); annual shoot taper for each year in MS (g) and UMS (h). 
Fig. 4 - Frequency distribution of growth units' length and growth units longer than $75 \mathrm{~cm}$ (inserted histogram) for (a) MS and (b) UMS. Average growth unit lengths along the stems for (c) MS and (d) UMS. The $x$ axis shows the growth unit position as age "dot" position in the annual shoot (i.e., 11.3 means annual shoot 11, growth unit 3), the $Y$-axis shows the length of the average growth unit (in $\mathrm{cm}$ ). The upper line in each graph shows the smoothed evolution of the size of first growth unit of the annual shoots.

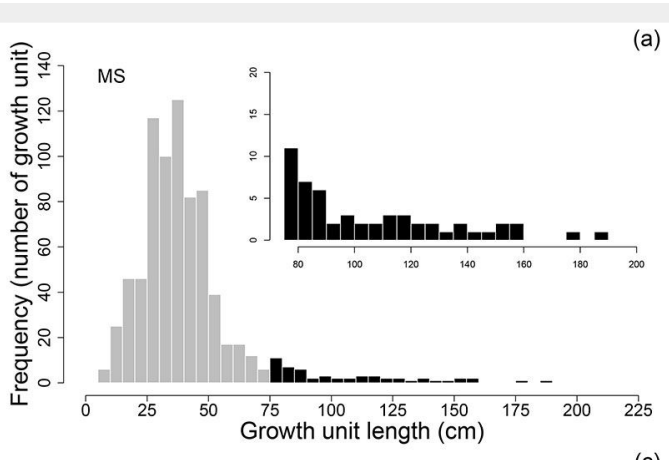

(a)

(c)

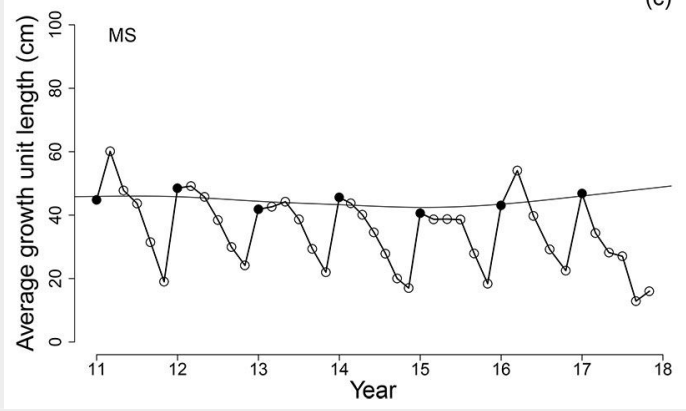

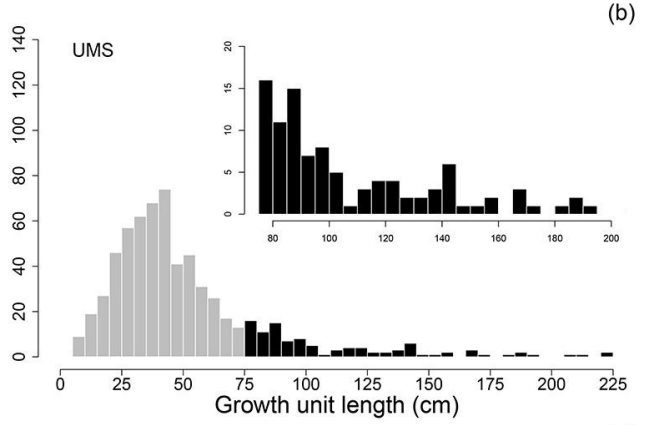

(b)

(d)

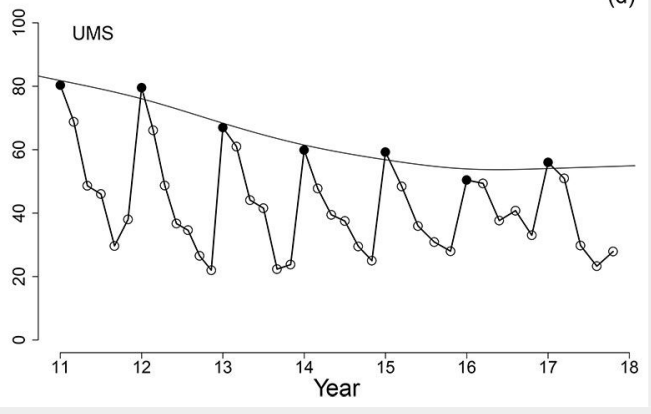

\section{Morphological analyses}

During the studied period (years 11 through 17), trees in the MS had more growth units per annual shoots than those in the UMS. The robust ANCOVA (non-parametric) showed that these differences were significant $(p<0.005)$ in all the evaluated years (Fig. 2a). There were no statistical differences ( $p>0.05)$ in number of branches and cones between the two plots (Fig. 2b). Number of branches per growth unit was around 5-6 in both stands and slightly decreased after year $15^{\text {th }}$.

Fig. $3 a$ and Fig. 3b presented a different behavior of total annual shoot length depending on the period of analysis, considering a first period between year $11^{\text {th }}$ to $13^{\text {th }}$, and a second period between year $14^{\text {th }}$ to $17^{\text {th }}$. The regression tree and the repeated measures ANCOVA also showed this difference. Until year $13^{\text {th }}$ both the year and the treatment were statistically significant ( $\mathrm{p}=0.0356$ and $\mathrm{p}=0.0001$ respectively), showing the UMS longer annual shoots. On the contrary, from year $14^{\text {th }}$ to $17^{\text {th }}$ the MS had longer annual shoots, being the treatment not statistically significant, but only the year $16(p=2.6 e-5)$. The shoots were shorter when they were grown later on time.

During the whole considered period (year $11^{\text {th }}-17^{\text {th }}$ ) the mean growth unit length of the UMS were longer than the growth units of the MS ( $p<0.0002$ - Fig. $3 c$, Fig. $3 d)$. The regression tree obtained for this variable showed year $12^{\text {th }}$ as a break point. After year $12^{\text {th }}$ the difference between the treatments was lower but still significant $(p=0.0157)$. Summarizing, the MS had shorter growth units but more of them during the period between the year $11^{\text {th }}$ $17^{\text {th }}$.

To further study the effects of silvicultural management on branches, mean branch diameter in the last cluster of each annual shoot was compared. In radiata pine, the last cluster of the year is generally the most vigorous one, showing bigger branches (the acrotony effect of radiata pine - Pont 2001). The regression tree showed the same pattern as the annual shoot length, with a break point in year $13^{\text {th }}$, being the branches of the MS stand larger than those of the UMS $(p=0.0187$ -
Fig. 3e, Fig. $3 f$ ) for this period. Considering the taper variable, the annual shoots of the MS had a higher taper index than those of the UMS during all the studied years ( $p<$ 0.0001 - Fig. 3g, Fig. 3h). These values increased as the study period progressed, becoming quite stable in the last years for the MS, but decreased at year $16^{\text {th }}$ and $17^{\text {th }}$ for the UMS.

Regarding the number of growth units longer than or equal to $75 \mathrm{~cm}$ both UMS and MS showed a decreasing number of long growth units through the years (Fig. 4). However, the UMS (Fig. 4b) showed a higher frequency of larger growth units compared to the MS (Fig. 4a). First growth units (black dots in Fig. $4 \mathrm{c}$ and Fig. 4d) were in the range of 50 to $90 \mathrm{~cm}$ long in the UMS and in the range of 40 to $50 \mathrm{~cm}$ long in the MS. The length difference between the first and the last growth units of each annual shoot was more dramatic in the UMS than in the MS.

\section{Log characterization}

For the characterization of the logs, the stems were divided in 5 logs of 4 meters

Tab. 2 - Mean and standard deviation of internode index $(I I)$, taper index $\left(\mathrm{cm} \mathrm{m}^{-1}\right)$, minimum diameter of the log $(\mathrm{cm})$, and log volume $\left(\mathrm{m}^{3}\right)$ for the first 5 logs of $4 \mathrm{~m}$ each. Statistically significant differences $(\mathrm{p}<0.05)$ between managed $(M S)$ and unmanaged stand (UMS) within a log marked with an asterisk $(*)$.

\begin{tabular}{llcccc}
\hline Log & Variable & Internode Index & Taper Index & Min. diameter log & Log volume \\
\hline $1^{\text {st }} \log (0$ to $4 \mathrm{~m})$ & UMS & $0.30 \pm 0.18$ & $2.05 \pm 0.71$ & $20.5 \pm 5.9$ & $0.21 \pm 0.11$ \\
& MS & $0.36 \pm 0.23$ & $2.20 \pm 0.66$ & $25.2 \pm 5.2^{*}$ & $0.29 \pm 0.11^{*}$ \\
$2^{\text {nd }} \log (4$ to $8 \mathrm{~m})$ & UMS & $0.48 \pm 0.27$ & $0.61 \pm 0.30$ & $18.3 \pm 5.8$ & $0.13 \pm 0.08$ \\
& MS & $0.38 \pm 0.24$ & $0.84 \pm 0.35^{*}$ & $21.7 \pm 4.3^{*}$ & $0.18 \pm 0.07^{*}$ \\
$3^{\text {rd }} \log (8$ to $12 \mathrm{~m})$ & UMS & $0.44 \pm 0.27$ & $0.67 \pm 0.21$ & $15.6 \pm 5.2$ & $0.10 \pm 0.06$ \\
& MS & $0.27 \pm 0.28^{*}$ & $0.82 \pm 0.28^{*}$ & $18.3 \pm 4.0^{*}$ & $0.13 \pm 0.05^{*}$ \\
$4^{\text {th }} \log (12$ to $16 \mathrm{~m})$ & UMS & $0.31 \pm 0.29$ & $0.82 \pm 0.22$ & $12.3 \pm 4.8$ & $0.07 \pm 0.05$ \\
& MS & $0.14 \pm 0.19^{*}$ & $0.96 \pm 0.26^{*}$ & $14.3 \pm 3.9$ & $0.09 \pm 0.04$ \\
\hline $5^{\text {th }} \log (16$ to $20 \mathrm{~m})$ & UMS & $0.25 \pm 0.26$ & $1.13 \pm 0.27$ & $8.4 \pm 4.3$ & $0.04 \pm 0.03$ \\
& MS & $0.11 \pm 0.16^{*}$ & $0.97 \pm 1.52$ & $10.3 \pm 5.2$ & $0.06 \pm 0.03$ \\
\hline
\end{tabular}




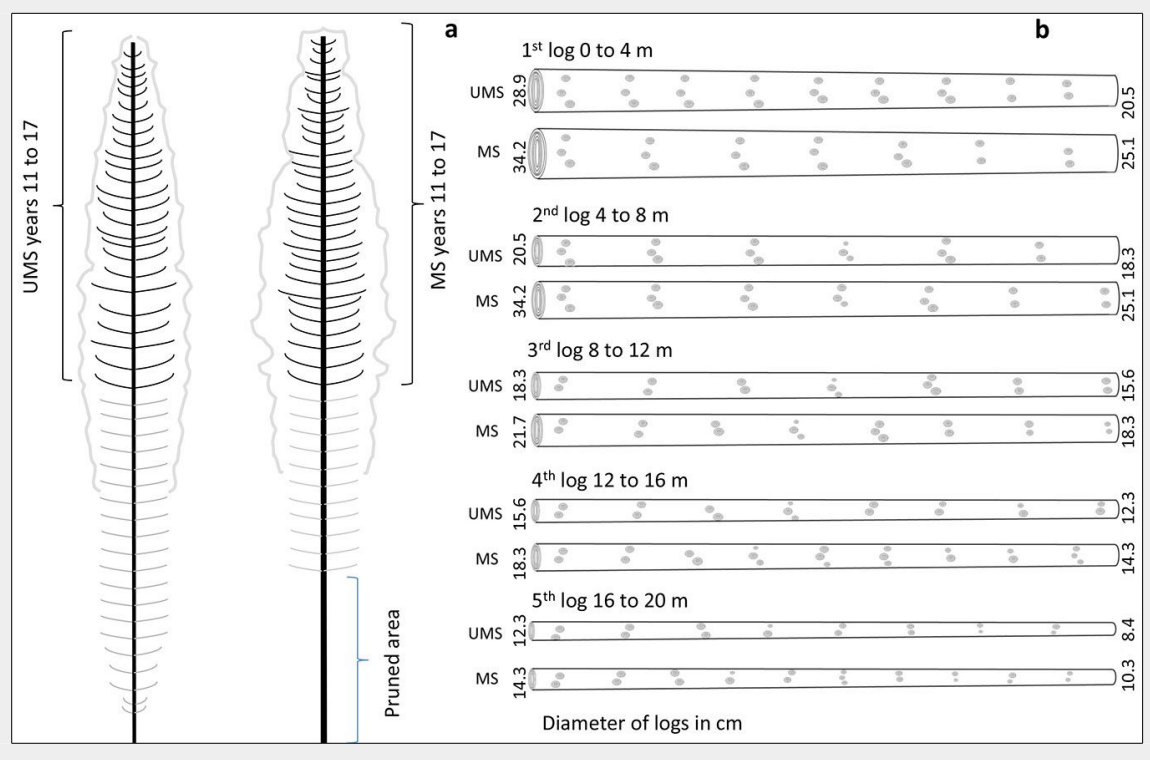

Fig. 5 - (a) Standing trees characteristics and (b) average log characterization with minimum and maximum log diameter and average branches per log for the managed (MS) and unmanaged stands (UMS).

each. The first log was accounted starting from the bottom of the stem. In most of the logs $\left(2^{\text {nd }}\right.$ to $\left.5^{\text {th }}\right)$ the Internode Index (II) was higher in the UMS (between 0.25 and 0.48 ) than in the MS (between 0.11 and $0.38, p<0.001-$ Tab. 2). On the other hand, taper Index (TI) was higher in the MS for most of the logs ( $1^{\text {st }}$ to $\left.4^{\text {th }}, \mathrm{p}<0.001\right)$, showing logs with more taper. Considering the size of the logs, volume was higher in all the MS logs. Fig. 5 shows the average characteristics of the logs from both, the MS and the UMS. Average maximum and minimum log diameter was bigger for all logs in the MS. Growth units were also more abundant in the MS for all logs, compared to the UMS, except the first log.

\section{Discussion}

Generally, the effect of forest management on radiata pine has been evaluated in terms of dry matter production (Beets \& Madgwick 1988), diameter and height growth rate, as well as taper form and clear stem length. Thinning, for instance, changes the growth rate of the remaining trees and increases the diameter growth rate, taper form, and branch diameter (Haygreen \& Bowyer 1996) as also has been reported for Mediterranean pine species (Moreno-Fernández et al. 2014). Heavy pruning, in general, reduces growth rate of trees (Neilsen \& Pinkard 2003) and creates more cylindrical trees, but the effect on the remaining branches is not fully clear. Furthermore, the combined effects of thinning and pruning have not been widely studied (Clark et al. 2004, Carson et al. 2014), although the combination is common in, for instance, commercial radiata pine plantations in Chile. Meneses \& Guzmán (2000) determined that the best value of the tree is derived from the basal log, whereas pruning higher clusters slows down the global growth of the trees. In our results, effect of thinning combined with pruning resulted in larger individual tree volumes in the stand with management (MS), but with larger taper index and more but shorter growth units.

Given that the MS was simultaneously thinned and pruned at years $6^{\text {th }}$ and $11^{\text {th }}$, the results showed that the combined management actions increased the number of growth units per annual shoot and decreased their internode length. Annual shoots were larger in the UMS during years $11^{\text {th }}$ to $13^{\text {th }}$; afterwards both stands presented similar annual shoots length, slightly larger in the MS (but without significant differences). Thus, during years $14^{\text {th }}$ to $17^{\text {th }}$, annual shoots were similar but the number of growth units was larger in the MS (and therefore the growth units were shorter Fig. 3). One possible explanation is that pruning in Chile is done on green branches, reducing the photosynthetic capacity of the tree, so that the trees produce more clusters to compensate the loss of photosynthetic capacity and equivalent to more foliar biomass, as stated by Pinkard \& Beadle (2000). In our study the initial stand density was 2500 trees ha ${ }^{-1}$, which is a high value for the species and site conditions. First pruning was done together with a thinning reducing the tree number from 2500 to 1300 trees ha ${ }^{-1}$. Sheriff et al. (1996) found that in stands with high initial stand density, the productivity of individual trees increases rapidly after thinning because both foliar biomass and foliar efficiency increase ( $\mathrm{FE}=$ increase in biomass/foliage quantity). We did not measure foliar biomass increments or foliar efficiency, however, an allometric relationship between stem cross-section area and foliar biomass has been proposed for radiata pine (Fernández 2013). Thus, the larger number of clusters per year and larger stem diameter at different heights in the MS can be associated with a larger amount of foliage. Pruned trees within thinned stands are aided in this type of growth by the larger foliar biomass, foliar efficiency, and light use efficiency documented by Sheriff et al. (1996).

Within the first few years after the second management practices there were statistical differences for the studied variables, but those differences disappeared in later years in the annual shoot length and the mean branch diameter, corresponding with the estimated canopy closure of the MS (year $14^{\text {th }}$ ). It might be possible that several years after the management practices, their effect on the trees were diminished as the crown repaired the foliage loss. Also, as the two plots approached a similar level of canopy closure in the later years of the study period, light and temperature levels in the two stands became more similar. This may also reduce growth differences between the plots, as growth units' production depends on these environmental factors (Fernández et al. 2011). During the whole period there were more units per annual shoot but shorter ones in the MS. This shows a long-term effect of pruning and thinning on branchiness of managed trees. In any event, both plots showed a tendency for decreasing growth over the years, a tendency already documented by Fernández et al. (2007) for the same species.

The frequency of internodes longer than $75 \mathrm{~cm}$ was clearly higher in the UMS than in the MS among annual shoots of similar size, which indicates that pruning together with thinning leads to trees with more and shorter growth units, but annual shoots of similar total size. This contradicts the findings of Grace et al. (1999), in which the number of clusters in radiata pine was correlated with annual shoot length; so longer annual shoots had more internodes.

Looking at the results of the branch analysis (Fig. 2), the number of branches per cluster was not directly affected by stand characteristics and management actions, similar to the results of Woollons et al. (2002). For instance, Grace et al. (1999) pointed out that, for radiata pine, the number of branches per cluster was independent of the number of clusters in an annual shoot, the position of the cluster within the annual shoot, and the number of stems per hectare. For the same species but located in different environment, Fernández et al. (2007) showed that number of branches per cluster was fairly consistent throughout the life of the tree, especially after the first years of establishment. Madgwick (1994) considered it a factor strongly controlled by genetics. In many studies, it has been demonstrated that the number of branches is related to the vigor of the tree, so tree size variables are more predictive of the number of branches than stand characteristics (Mäkinen \& Colin 1998). 
Similarly, Woollons et al. (2002) found that the inclusion of stand variables in a model to predict the number of branches per clus ter in radiata pine was not justified. In our study, trees in the MS subject to pruning afterward compensate the decrease in photosynthetic capacity by producing more growth units per year, instead of more branches per growth unit.

According to our results, the effect of stand management on branch diameter shows that when thinning is performed, the growing space and resources for the remaining trees increase, generally allowing the enlargement of branches, as could be seen during years $11^{\text {th }}$ to $13^{\text {th }}$, with significant differences. It has been also reported by other authors like Haygreen \& Bowyer (1996) and Gort et al. (2010). As stand closure occurs, the differences in the following years disappear.

Previous studies regarding the effects of thinning on tree taper produced similar results to ours (Fig. 3g, Fig. 3h). Pape (1999) found in Picea abies that the stands with the heaviest thinning showed the highest taper and the stands with natural thinning showed the lowest taper. After thinning, the remaining trees use the additional space to grow more in diameter and less in height, changing the growth pattern of trees (Zobel \& Van Buijtenen 1989). On the other hand, trees with less space, as in the UMS, grow less in diameter, making more slender trees with less taper.

Concerning the effects of pruning on taper form, Långström \& Hellqvist (1991) concluded that strong pruning of green branches affects tree development, reducing the diameter growth of the lower part of the tree and making more cylindrical stems. In our study, the differences between the UMS and MS in taper form were always significant. This result might be a reaction to the strong pruning and thinning in year 11 (much stronger than in the intervention in year 6 ).

In our assessment of stem characteristics, using the five virtual logs per stand (Tab. 2, Fig. 5), we found that the MS logs showed greater minimum top diameter in the 3 basal logs as well as bigger volume. However, logs from the UMS showed better sawn wood quality properties, such as bigger internode index (logs $2^{\text {nd }}$ to $5^{\text {th }}$ ) and lower taper index (logs $2^{\text {nd }}$ to $4^{\text {th }}$ ). Thus, thinning and pruning together produced logs with more branch clusters, shorter internodes, and more taper (Fig. 5). Although this was the tendency, these differences were not significant for all logs.

\section{Conclusions}

The study focused on the effect of the classical management practice of thinning together with pruning in radiata pine. Even if this practice is generally used in Chile, the real practical effects were not yet studied for this region. The combined management generated larger volumes of wood and clear wood in the pruned logs, and changed the wood quality properties of the unpruned stem section for a number of years after the silvicultural interventions. The managed trees after the treatments showed more growth units per annual shoot with shorter internodes, thus generating more knotty wood. Although differences between trees in MS and UMS decreased or disappeared as trees of the managed plot restored the foliar biomass lost due to pruning, and as the canopy closure in the two plots approached an equal level, the deleterious effects of management on sawn wood quality are clear in the commercial logs between 4 and $16 \mathrm{~m}$ height. The study is based in an un-replicated experiment and mixing both treatments (pruning and thinning). Therefore, we suggest further research with replicated samples and separating the effect of both management practices in Chilean growing conditions.

\section{Acknowledgements}

This research were partially financed by Chilean FONDECYT Grant 11085008, by the Marie Curie Action ForEAdapt project funded by the European Union Seventh Framework Programme (FP7-PEOPLE-2010IRSES) under Grant Agreement No. PIRSESGA-2010-269257 and the SuFoRun project funded by the European Union's H2O2O Research and Innovation Programme under the Marie Sklodowska-Curie Grant Agreement No. 691149. Ane ZubizarretaGerendiain also acknowledges the financial support of the FCT (SFRH/BPD/63979/ 2009) and the UEF Foundation (Project 930341). Ricardo Olea also acknowledges the financial support of the FONDECYT Grant 11121128. We thanks Forestal Bagaro S.A. for the possibility to work with their radiata pine plantations.

\section{References}

Bannister MH (1962). Some variations in the growth pattern of Pinus radiata in New Zealand. New Zealand Journal of Forestry Science 5: 342-370. [online] URL: http://www.cabdirect. org/cabdirect/abstract/19620603401

Beets PN, Madgwick HAI (1988). Above-ground dry matter and nutrient content of Pinus radiata as affected by lupin, fertilizer, thinning, and stand age. New Zealand Journal of Forestry Science 18 (1): 43-64. [online] URL: http://www. scionresearch.com/_data/assets/pdf_file/0005 130569/NZJFS1811988BEETS43_64.pdf

Burdon RD (1971). Clonal repeatabilities and clone-site interactions in Pinus radiata. Silvae Genetica 20: 33-39.

Cabello M (2005). Podas y raleos [Prunings and thinnings] In: "Manual Práctico de Manejo. Simulador de árbol individual para Pino radiata (Pinus radiata D. Don): arquitectura de copa y calidad de madera" (Peters R ed). Fundación Chile - FONDEF Conicyt, Santiago, Chile, pp. 5770.

Caraglio Y, Barthélémy D (1997). Revue critique des termes relatifs à la croissance et à a la ramification des tiges des végéteaux vasculaires [Critical revision of terms related to growth and a branching vascular vegetative stem]. In: "Modélisation et simulation de l'architecture des végéteaux" (Bouchon J, Reffye Ph, Barthélémy $D$ eds). INRA Editions, Paris, France, pp. 11-87.

Carson SD, Cown DJ, McKinley RB, Moore JR (2014). Effects of site. silviculture and seedlot on wood density and estimated wood stiffness in radiata pine at mid-rotation. New Zealand Journal of Forestry Science 44 (1): 26. - doi: 10.1186/s40490-014-0026-3

CIREN (1999). Estudio agrológico VIII Región. Descripciones de suelos. Materiales y símbolos. [Agrologic study of Region VII. Soils description. Materials and symbols]. Publication CIREN no. 121, vol. 2, Santiago, Chile, pp. 586.

Clark III A, Strub M, Anderson LR, Lloyd HG, Daniels RF, Scarborough JH (2004). Impact of early pruning and thinning on lumber grade yield from Loblolly pine. In: Proceedings of the " $12^{\text {th }}$ Biennial Southern Silvicultural Research Conference" (Connor KF eds). Gen. Tech. Rep. SRS-71, USDA Forest Service, Asheville, NC, USA, pp. 594. [online] URL: http://www.tree search.fs.fed.us/pubs/6642

Faraway JJ (2016). Extending the linear model with R: generalized linear, mixed effects and nonparametric regression models. Series Texts in Statistical Science (vol. 124), Chapman \& Hall/CRC Press, Boca Raton, FL, USA, pp 400. Fernández MP (2013). Understanding and tuning some allometric relationships useful for functional-structural plant modeling. In: Proceedings of the " 7 th International Conference on Functional-Structural Plant Models" (Sievänen R, Nikinmaa E, Godin C, Lintunen A, Nygren P eds). Saariselkä (Finland) 9-14 Jun 2013. Finnish Society of Forest Science, Vantaa, Finland Finnish Forest Research Institute, Vantaa, Finland - Department of Forest Sciences, University of Helsinki, Helsinki, Finland, pp 162-164.

Fernández MP, Norero A (2006). Allometric study on radiata pine branches (Pinus radiata D. Don). Scandinavian Journal Forest Research 21: 124-129. - doi: 10.1080/02827580500533177

Fernández MP, Norero A, Barthélémy $D$, Vera J (2007). Morphological trends in main stem of Pinus radiata $\mathrm{D}$. Don: transition between vegetative and reproductive phase. Scandinavian Journal Forest Research 22: 398-406. - doi: 10.1080/02827580701610261

Fernández MP, Norero A, Vera J, Perez E (2011). A functional-structural model for radiata pine (Pinus radiata) focusing on tree architecture and wood quality. Annals of Botany 108: 11551178. - doi: 10.1093/aob/mcr156

Gort J, Zubizarreta Gerendiain A, Peltola H, Kilpeläinen $A$, Pulkkinen $P$, Jaatinen $R$, Kellomäki $S$ (2010). Differences in branch characteristics of Scots pine (Pinus sylvestris L.) genetic entries grown at different spacing. Annals of Forest Science 67 (7): 705-705. - doi: 10.1051/forest/20 10030

Grace JC, Carson MJ (1993). Prediction of internode length in Pinus radiata stands. New Zealand Journal of Forest Science 23 (1): 10-26.

Grace JC, Pont D, Goulding CJ, Rawley B (1999). Modelling branch development for forest management. New Zealand Journal of Forest Science 29 (3): 391-408. [online] URL: http://www. scionresearch.com/ data/assets/pdf file/0004 
|17239/NZJFS293_1999_391_408GRACE.pdf Hallé F, Oldeman RAA, Tomlinson PB (1978). Tropical trees and forests, an architectural analysis. Springer Verlag, Berlin, Heidelberg, New York, pp. 441.

Haygreen JG, Bowyer JL (1996). Forest products and wood science: an introduction ( $3^{\text {rd }}$ edn). lowa State University Press, lowa, USA, pp. 484.

Kininmonth JA, Whiteside ID (1991). Forest Research Institute, New Zealand Ministry of Forestry, Rotorua, New Zealand, pp. 216.

Långström B, Hellqvist C (1991). Effects of different pruning regimes on growth and sapwood area of Scots pine. Forest Ecology and Management 44 (2-4): 239-254. - doi: 10.1016/03781127(91)90011-J

Madgwick HAI (1994). Pinus radiata: biomass, form, and growth. Pers. Publ. Rotorua, New Zealand, pp. 428. [online] URL: http://www. cabdirect.org/cabdirect/abstract/19940603666 Meneses M, Guzmán S (2000). Análisis de la eficiencia de la silvicultura destinada a la obtención de madera libre de nudos en plantaciones de pino radiata en Chile [Efficiency of the silviculture used to obtain free of knots wood in radiata pine plantations grown in Chile]. Bosque 21 (2): 85-93. - doi: 10.4206/bosque.2000.v 21n2-07

Meneses M, Velasco R (1992). Efectos del raleo y la poda en el crecimiento diametral de ramas. [Effects of thinning and pruning on the diamater growth of branches]. MSc Forest Engineer degree, Universidad Austral de Chile, Valdivia, Chile, pp. 120.

Mezzano SA (1998). Predicción del aprovechamiento y calidad de madera aserrada de Pinus radiata $\mathrm{D}$. Don a partir de variables de las trozas [Prediction of the approfitability and quality of sawn wood of Pinus radiata D. Don from log production]. Thesis for Forest Engineer, Universidad Austral de Chile, Valdivia, Chile, pp. 57.

Mair P, Schoenbrot F, Wilcox R (2016). WRS2: Wilcox robust estimation and testing. Web site. [online] URL: http://cran.r-project.org/web/pa ckages/WRS2/citation.html

Mäkinen H, Colin F (1998). Predicting branch angle and branch diameter of Scots pine from usual tree measurements and stand structural information. Canadian Journal Forest Research 28: 1686-1696. - doi: 10.1139/x98-141

Mäkinen H, Verkasalo E, Tuimala A (2014). Effects of pruning in Norway spruce on tree growth and grading of sawn boards in Finland. Forestry 87 (3): 417-424. - doi: 10.1093/forestry/ cpto62

Moreno-Fernández D, Sánchez-González M, González JG, Hevia A, Majada JP, Cañellas I, GeaIzquierdo $G$ (2014). Response to the interaction of thinning and pruning of pine species in Mediterranean mountains. European Journal Forest Research 133: 833-843. - doi: 10.1007/s10 342-014-0800-z

Neilsen WA, Pinkard EA (2003). Effects of green pruning on growth of Pinus radiata. Canadian Journal Forest Research 33: 2067-2073. - doi: 10.1139/x03-131

Olea R, Palma W, Rubio P (2015). LSTS: Locally Stationary Time Series. R package version 1.0, web site. [online] URL: http://cran.r-project. org/web/packages/LSTS/index.html

Pape R (1999). Effects of thinning regime on the wood properties and stem quality of Picea abies. Scandinavian Journal Forest Research 14: 38-50. - doi: 10.1080/02827589908540807

Pawsey CK (1964). Height and diameter growth cycles in Pinus radiata. Austrian Forest Research 1: 3-8.

Peltola H, Kilpelainen A, Sauvala K, Raaisainen T, IkonenVP (2007). Effects of early thinning regime and tree status on the radial growth and wood density of Scots pine. Silva Fennica 41 (3): 489-505. - doi: 10.14214/sf.285

Pinkard EA, Beadle Cl (2000). A physiological approach to pruning. The International Forestry Review 2 (4): 295-305. [online] URL: http://www.jstor.org/stable/42609327

Pont D (2001). Use of phyllotaxis to predict arrangement and size of branches in Pinus radiata. New Zealand Journal of Forest Science 31 (2): 247-262. [online] URL: http://www.scion research.com/_data/assets/pdf_file/0019/17119 /Reprint-2773.pdf

Prodan M, Peters R, Cox F, Del Real P (1997).
Mensura forestal [Forest mensuration]. Deutsche Gesellschaft für Technische Zusammenarbeit (GTZ) $\mathrm{GmbH}$, Instituto Interamericano de Cooperación para la Agricultura (IICA), Serie Investigación y Educación en Desarrollo Sostenible IICA, San José, Costa Rica, pp. 586.

R Core Team (2016). R: a language and environment for statistical computing. R Foundation for Statistical Computing, Vienna, Austria, pp. 3501. [online] URL: http://www.r-project.org Ripley B (2016). Tree: Classification and regression trees. $\mathrm{R}$ package version 1.0-37, web site. [online] URL: http://cran.r-project.org/web/pac kages/tree/index.html

Santibáñez F, Uribe JM (1993). Atlas agroclimático de Chile: regiones sexta, séptima, octava y novena [Agroclimatic atlas of Chile: sixth, seventh, eighth and ninths region]. Ministry of Agriculture, Santiago, Chile, pp. 99.

Sheriff DW, Mattay JP, McMurtrie RE (1996). Modeling productivity and transpiration of $\mathrm{Pi}$ nus radiata: climatic effects. Tree Physiology 16: 183-186. - doi: 10.1093/treephys/16.1-2.183 Todoroki CL, West GG, Knowles RL (2001). Sensitivity analysis of log and branch characteristics influencing sawn timber grade. New Zealand Journal of Forest Science 31 (1): 101-119. [online] URL: http://www.scionresearch.com/_data/as sets/pdf_file/0010/17011/Reprint-2760.pdf

Wilcox RR (2012). Introduction to robust estimation and hypothesis testing. Academic Press, Elsevier, Amsterdam, Netherlands, pp. 690.

Woollons RC, Haywoodb A, McNicklec DC (2002). Modeling internode length and branch characteristics for Pinus radiata in New Zealand. Forest Ecology Management 160: 243-261. - doi: 10.1016/S0378-1127(01)00468-6

Zobel BJ, Van Buijtenen JP (1989). Wood variation: its causes and control. Springer-Verlag, Berlin, Germany, pp. 363. - doi: 10.1007/978-3-64 2-74069-5

Zubizarreta-Gerendiain A, Peltola H, Pulikkinen $P$, Kellomäki S (2009). Effects of genetic entry and competition by neighbouring trees on growth and wood properties of cloned Norway spruce (Picea abies). Annals of Forest Science 66 (8): 806-806. - doi: 10.1051/forest/2009075 